\author{
Cadernos de \\ ESTUdOS LingiülístICOS - (55.2), Campinas, Jul./Dez. 2013
}

\title{
VERBOS METEOROLÓGICOS, INDEXICAIS E MONSTROS ESPACIAIS
}

\author{
LOVANIA ROEHRIG TEIXEIRA* \\ RENATO MIGUEL BASSO**
}

\begin{abstract}
RESUMO: Este artigo apresenta três abordagens para as sentenças meteorológicas como 'Tá chovendo': (i) defende que 'chover' é um predicado de zero-lugar; (ii) afirma que 'chover' tem um espaço argumental para localização; e, (iii) a Abordagem Indexical, que declara que 'chover' é um indexical, pois depende do contexto para receber seu valor semântico. Uma vez aceita a Abordagem Indexical para as sentenças meteorológicas, é possível encontrar um monstro no domínio espacial, que assim é definido por Kaplan (1989) por mudar o contexto de avaliação dos indexicais em seu escopo. O monstro, nesses casos, é o verbo de dizer que permite que 'tá chovendo' seja avaliado em relação à localização do contexto reportado e não em relação à localização do contexto de proferimento - único contexto disponível de acordo com a teoria kaplaniana. A existência de monstros espaciais acaba com uma assimetria com relação ao contexto kaplaniano, pois a coordenada espacial era a única que até então não era alvo de um operador-monstro.
\end{abstract}

PALAVRAS-CHAVE: sentenças meteorológicas; indexicais; mudança de contexto.

ABSTRACT: This paper presents three approaches to meteorological sentences like 'Tá chovendo': (i) states that 'chover' is a zero-place predicate; (ii) states that 'chover' carry an argument slot for a location; and, (iii) the Indexical Approach, which states that 'chover' is an indexical and depends on context to receive its semantic value. Once accepted the Indexical Approach to meteorological sentences, it is possible to find a space monster, defined by Kaplan (1989) as one operator that can shift the context of evaluation of indexicals. In this way, monsters are the saying verbs because in meteorological sentences, like 'tá chovendo', they can shift the local of the context of evaluation from the utterance context to the reported context. The existence of the space monster takes away an asymmetry in respect to the kaplanian context, since until now the local coordinate was the only one that was not the target of a monster-operator.

KEY WORDS: meteorological sentences; indexicals; context shifting.

\section{INTRODUÇÃO}

Sentenças com verbos meteorológicos, das quais o exemplo mais famoso é 'Tá chovendo', suscitam uma série de problemas complexos para a semântica, a pragmática e a sintaxe das línguas naturais. As principais razões para tanto se relacionam com as condições de verdade e com o fato de elas envolverem, ou

\footnotetext{
*lovaniateixeira@gmail.com

***rmbasso@gmail.com
} 
não, uma posição argumental para o lugar em que o evento - no caso, chover acontece. Há pelo menos três linhas diferentes que respondem a essas questões: (i) uma delas defende que não há argumento de lugar envolvido em 'Tá chovendo' e que essa sentença trata de um lugar específico devido a um processo pragmático de "enriquecimento livre"; (ii) outra linha defende que há um argumento de lugar não pronunciado na estrutura de 'Tá chovendo' e, portanto, a representação lógica dessa sentença envolve esse argumento, mas a estrutura superficial não; e (iii) há uma alternativa que sugere que tal sentença envolve, na verdade, um indexical, que seria o verbo 'chover' (como os itens 'eu', 'aqui', 'hoje'), e assim ele só receberia um valor semântico com relação a um contexto específico que fornece um valor para lugar.

Neste artigo, não defenderemos nenhuma dessas abordagens, mas mostraremos que a abordagem indexical (a (iii)) pode dar vez a operadoresmonstros, conforme definidos por Kaplan (1989), que atuariam no domínio espacial. Essa discussão desperta interesse porque alguns autores, como Schlenker (1999, 2003, 2010) e Teixeira (2012) encontraram, em língua natural, operadores-monstros no domínio temporal e pronominal, e Predelli (2008) e Basso \& Teixeira (2011) argumentaram que há operadores-monstros no domínio modal, mas ainda não foi encontrado - até onde sabemos - esse tipo de operador no domínio espacial, gerando uma assimetria não desejada entre as coordenadas do contexto kaplaniano.

Com o propósito de defender a existência de operadores-monstros no domínio espacial - desde que se aceite uma teoria indexical para os verbos meteorológicos -, o presente artigo está assim organizado: na seção 1, apresentaremos as três abordagens das sentenças meteorológicas que descrevemos acima em poucas palavras, sem defender nenhuma delas; na seção 2, apresentaremos a teoria para os indexicais proposta por Kaplan (1989), a dos operadores-monstros de Schlenker (1999, 2003, 2010) e, a título de exemplificação, apresentaremos alguns dos indexicais temporais monstruosos do português brasileiro (PB); na seção 3, voltaremos à abordagem indexical para os verbos meteorológicos usando a teoria de Kaplan, e defenderemos a existência de operadores-monstros espaciais, a partir de certas assunções sobre as sentenças meteorológicas; finalmente, na conclusão, retomaremos o percurso aqui feito e exporemos as consequências da existência de monstros no domínio espacial.

\section{TRÊS PONTOS DE VISTAS SOBRE AS SENTENÇAS METEOROLÓGICAS}

A principal questão que analisaremos neste artigo com relação às sentenças meteorológicas refere-se às suas condições de verdade, mais especificamente, se uma sentença como 'Tá chovendo' expressa uma proposição sem a necessidade de haver uma localização envolvida, ou se essa localização é necessária para que 'Tá chovendo' veicule uma proposição. Nas seções seguintes, apresentaremos as três abordagens que procuram estabelecer as condições de verdade das sentenças meteorológicas: a primeira delas defende que não há argumento de lugar envolvido 
em 'Tá chovendo'; por sua vez, a segunda defende que há um argumento de lugar não pronunciado na estrutura das sentenças meteorológicas; e, finalmente, a terceira sugere que os verbos meteorológicos são indexicais e só recebem valor semântico se fixados num contexto específico.

\subsection{Nenhum argumento de lugar}

Recanati $(2002,2007)$ talvez seja o principal defensor da ideia de que as sentenças meteorológicas não dispõem de um espaço para um argumento de localização, i.e., que são sentenças de zero-lugar. Para o autor, a localização emerge por razões pragmáticas e não por razões semânticas, já que as sentenças meteorológicas têm uma interpretação indefinida de localização quando essa informação está implícita. Em suma, na concepção de Recanati (2002, 2007), 'chover' é um predicado que: (i) não é saturado por argumentos de lugar; e (ii) necessita de atribuição de localização apenas por razões pragmáticas. Nas palavras do autor, "What I will deny [...] is that 'rain' carries an implicit location argument." (RECANATI, 2007, p.125).

Um dos principais argumentos favoráveis à sua teoria é o chamado "caso do meteorologista" (cf. Recanati 2002): imagine um cenário no qual chover no planeta Terra se tornou algo raro e extremamente importante, de modo que, para sabermos quando um tal evento dessa importância e raridade ocorre, foi instalada em todo o globo uma série de detectores de chuva, que são monitorados a partir de uma única sala. Se chover, não importa onde, um dos detectores disparará um (único) alarme. Imagine então que um dos funcionários escute o alarme tocar e grite: 'Tá chovendo!' - a ideia é que esse proferimento expressa uma proposição verdadeira desde que esteja chovendo no momento em que ele ocorre, não importa em que lugar.

Partindo do contexto acima, Recanati sugere que somente uma interpretação indefinida da localização do evento está disponível para (1), conforme mostra a paráfrase dessa interpretação em (2):

(1) Tá chovendo!

(2) Tá chovendo em algum lugar.

Tendo demonstrado, com o caso do meteorologista, que é possível obter uma interpretação indefinida de lugar para sentenças meteorológicas, Recanati (2007), na sequência, defende que os predicados meteorológicos não dispõem de uma posição para o argumento de lugar. Para tanto, o autor compara a interpretação do predicado 'comer', que também tem um argumento implícito com leitura indefinida, à interpretação de 'chover' no contexto do meteorologista. Segundo o autor, as interpretações de (1) e de (3) seriam semelhantes, considerando as paráfrases em (2) e (4), nas quais os argumentos indefinidos estão em itálico.

1 "O que eu negarei, portanto, é que 'chover' possui um argumento implícito de localização." (Tradução nossa). 
(3) João come.

(4) João come alguma coisa.

Note que o autor traça um paralelo entre 'chover' e 'comer' para mostrar que os dois predicados têm o mesmo comportamento: eles não precisam ser saturados por um argumento com interpretação definida. Sendo assim, não há nada de especial com 'chover' e nem com os demais verbos meteorológicos, o que podemos verificar pelas condições de verdade (fornecidas de modo bastante simplificado) em (1') e em (3').

(1') 'Tá chovendo' é verdadeira sse estar chovendo é o caso.

(3') 'João come' é verdadeira sse João comer é o caso.

Na concepção de Recanati sempre que um argumento implícito é interpretado indefinidamente (como ele afirma que é o caso da sentença (1)) há uma análise disponível (baseada no enriquecimento pragmático) que dispensa completamente a ideia de argumento implícito. Com essa ideia, o autor procura negar que predicados como 'chover' têm um lugar para o argumento de localização, e, assim, confirmaria que: (i) do ponto de vista semântico, 'chover' é um predicado de zero-lugar - não há argumento de localização envolvido em sua estrutura; (ii) do ponto de vista pragmático, um processo de enriquecimento (livre) frequentemente ocorre, e a sentença com 'chover' passa a ser mais informativa porque envolve um lugar específico - a ideia é que o enriquecimento pragmático torna a proposição específica a um lugar.

Recanati expõe suas ideias através da semântica de eventos neo-Davidsoniana e assume uma análise em que os verbos meteorológicos têm "[...] no 'standard' argument in the first place. In contrast to 'dance', which has a standard agent argument (introduced indirectly in logical form, [...]), 'rain' has no agent or theme [...]” (2007, p.128) $)^{2}$. Sendo assim, 'dançar' em (5) não exige um argumento de local, mas possui um argumento padrão - o agente - como representado em (6). Por seu turno, 'chover' em (7) não possui nem um argumento padrão nem um argumento de local, como observamos na representação em (8).

(5) Maria dança

(6) \$e [DANÇAR (e) \& AGENTE (Maria, e)]

(7) Tá chovendo

(8) \$e [CHOVER (e)]

No entanto, Recanati (2007) chama a atenção para a existência de predicados como 'chegar' em (9), que possuem tanto um argumento de localização e um argumento padrão, como representado em (10):

2 “[...] nenhum argumento 'padrão' em primeiro lugar. Em contraste com 'dançar', que tem um argumento padrão de agente (introduzido indiretamente na forma lógica [...]), 'chover’ não tem agente ou tema [...]" (Tradução nossa). 
(9) João chega

(10) \$e [CHEGAR (e) \& AGENTE (João, e) \& LOCALIZAÇÃO $\left(1^{3}\right.$, e)]

Como reforço teórico de sua abordagem, Recanati (2007, p.128) propõe o teste abaixo, considerando o contexto do "caso do meteorologista":

(11) A (meteorologista): Tá chovendo!

B: Onde?

A: Não tenho ideia.

(11) sugere que a localização, de fato, pode ter uma leitura indefinida. Por conta disso, "[...] the contextually specified location is not a genuine implicit argument in the 'rain' case. It is not a genuine implicit argument because, if it were, it would have to be provided in every context, including the context of the weatherman example (where no location is actually specified)" (2007, p.129) ${ }^{4}$. Com essa afirmação, Recanati (2002) completa sua argumentação em favor da ideia de que os predicados meteorológicos têm valência zero ${ }^{5}$.

No entanto, ainda é preciso esclarecer como Recanati conclui que a localização nas sentenças meteorológicas é uma informação decorrente de algum enriquecimento pragmático livre, e não de um processo semântico. Para isso, é preciso "[...] distinguish between the contextual provision of an implicit argument [fenômeno semântico] and the pragmatic process of 'free enrichment'." (RECANATI, 2007, p.128) .

Segundo Recanati (2007, p.128-129) o enriquecimento livre é um processo através do qual a interpretação de um proferimento torna-se contextualmente mais específica do que o significado literal da sentença proferida. Esse processo é top-down, não é exigido pelo material linguístico, i.e., é desenvolvido pelo ouvinte com o objetivo de amplificar a informatividade do que o falante está dizendo. Assim sendo, "The gap between sentence meaning and utterance meaning is bridged by world knowledge and contextual expectations." (RECANATI, 2007, p.129) ${ }^{7}$. Além disso, a principal característica desse processo pragmático é que ele é um processo opcional - pode ou não ocorrer, dependendo do contexto. Considere as sentenças em (12) e (13) baseadas nos exemplos de Recanati (2007).

\footnotetext{
${ }^{3}$ Na representação lógica dada por Recanati, ' 1 ' é uma variável livre que figura um espaço argumental que deve ser contextualmente atribuído.

4 “[...] a localização contextulamente especificada não é um argumento implícito genuíno no caso de 'chover'. Ela não é um argumento implícito genuíno, porque, se fosse, teria de ser fornecido em todos os contextos, incluindo o contexto do exemplo meteorologista (onde nenhuma localização é realmente especificada)." (Tradução nossa).

${ }^{5}$ E nos contextos mais gerais, como o predicado 'chover' se sai no teste? Ele reclama um argumento ou um adjunto? Considere a situação abaixo: "A: Tá chovendo! / B: Onde? / A: * Não tenho ideia”. Nesse caso, segundo o teste proposto do Recanati, 'chover' parece exigir um argumento de localização.

6 "[...] distinguir entre o fornecimento contextual de um argumento implícito e o processo pragmático de "enriquecimento livre" (Tradução nossa).

7 "A lacuna entre o significado da sentença e o significado do proferimento é preenchida pelo conhecimento de mundo e pelas expectativas contextuais." (Tradução nossa).
} 
(12) Maria gosta de usar coelho.

(13) Maria gosta de comer coelho.

Em (12), 'coelho' é interpretado em um sentido (específico) de 'pele de coelho', mesmo que a palavra 'coelho' signifique algo mais geral, e.g., 'coisas feitas de coelho'. Em (13), por sua vez, 'coelho'é interpretado como 'carne de coelho' devido ao acionamento do conhecimento de mundo ou das expectativas contextuais, já que nós sabemos que as pessoas comem carne de coelho, enquanto que elas usam pele de coelho em suas roupas e, além disso, nós esperamos que o falante diga coisas plausíveis. Agora considere a sentenças em (14) e (15):

(14) Uma vez, na Idade Média, choveu granizo por 2 dias seguidos. ${ }^{8}$

(15) Ontem, choveu.

(14) é interpretada adequadamente apesar de a localização do evento de 'chover' estar indefinida, ao passo que em (15) é necessário que se determine a localização da 'chuva', i.e., é exigida uma leitura definida de localização e sem ela não é possível ter uma ideia da proposição veiculada em (15). As diferenças nas interpretações geradas com 'chover' em (14) e (15) mostram que o predicado pode ser interpretado tendo uma localização definida ou indefinida, dependendo da situação. Esse comportamento leva Recanati a afirmar que a especificação contextual da localização do evento de 'chover' (em (15)) é opcional (fenômeno pragmático), e não é fruto do fornecimento contextual de um argumento implícito (fenômeno semântico e, por isso, obrigatório).

\subsection{Lugar - argumento implícito}

Segundo Corazza (2004) e Taylor (2001), entre outros, as sentenças meteorológicas necessitam de argumentos de localização para serem interpretadas, e assim, mesmo que esses elementos não estejam na superfície, i.e., não estejam realizados foneticamente, eles estão presentes na forma lógica como argumentos implícitos. Uma sentença como (16), assim, pode ser representada por (17), cujo argumento implícito está tachado:

(16) Tá chovendo.

(17) Tá chovendo aquit.

A ideia geral de Corazza (2004) é a de que os verbos como 'chover' são predicados que possuem uma posição argumental para a localização e, ao mesmo tempo, podem estar com essa informação implícita ${ }^{9}$. No entanto, apesar de a

\footnotetext{
${ }^{8}$ A sentença original de Recanati (2007) é 'Once, in Antiquity, it rained blood. Since then, no such thing ever happened again.'. No entanto, ela pode ser interpretada metaforicamente o que nos motivou a modificá-la neste artigo.

${ }^{9}$ Corazza se apoia na ideia de Perry (1993) que afirma que alguém pode pensar sobre um item sem representá-lo; o falante não precisa articular o item, se isso não for necessário.
} 
localização não estar expressa na superfície de sentenças como (16), ela deve estar representada no nível lógico, já que todos os elementos semanticamente relevantes podem estar: (i) realizados foneticamente ou (ii) serem argumentos implícitos. Por conta disso, as sentenças meteorológicas como (16) possuem argumentos que se encaixam em (ii), i.e, a localização é um argumento implícito.

Para argumentar que a determinação da localização em sentenças como (16) é um fenômeno semântico, ao contrário do que afirmara Recanati (2002, 2007), Corazza (2004) lança mão das condições de verdade das sentenças, já que na sua composição só incluímos elementos semanticamente relevantes.

O autor propõe uma comparação entre as condições de verdade de uma sentença em que a localização não é um argumento do predicado e uma sentença meteorológica em que a localização é um constituinte da proposição. Para ver como isso funciona, considere as sentenças em (16) e em (18) e as suas condições de verdade em (16') e em (18').

(16) Tá chovendo.

(16') 'Tá chovendo' é verdadeira sse estar chovendo é o caso no tempo t e na localização 1 .

(18) Maria tá atrasada.

(18') 'Maria tá atrasada' é verdadeira sse Maria está atrasada no tempo t.

Em (16), temos uma sentença semanticamente indeterminada, i.e., os argumentos de tempo e de localização não estão realizados foneticamente; no entanto, esses argumentos são exigidos no estabelecimento das condições de verdade em (16'), e isso sugere que eles resultam de um processo semântico. De outro modo, (18) é uma sentença semanticamente determinada (todos os seus argumentos estão realizados foneticamente), mas conceitualmente indeterminada (necessita de informações adicionais que serão fornecidas pragmaticamente ou através do fundo pressuposicional em que o proferimento ocorreu). Podemos ver que o tipo de informação demandada em (18) não entra na constituição das condições de verdade em (18'); nesse caso, a proposição já está completa e as informações adicionais são de caráter pragmático.

Em suma, as diferenças entre (16) e (18) se concentram no fato de que para (16) a localização e o tempo são constituintes exigidos pelas condições de verdade. Para (18), por sua vez, não é necessário acrescentar a localização às condições de verdade, nem é necessário saber para quê Maria está atrasada; esse tipo de enriquecimento é pragmático e não afeta o valor de verdade da proposição expressa por (18).

A partir da determinação das condições de verdade das sentenças meteorológicas, é possível, segundo Corazza (2004, p.72), mostrar que o predicado 'chover' " [...] is a two-place predicate which must be completed by a location and a time and can only so be completed $[\ldots]{ }^{10}$. Sendo assim, sentenças como (16) que são "[...] semantically

10 “[...] é um predicado de dois lugares que precisa ser preenchido com uma localização e um tempo e somente dessa forma pode ser completado [...]" (Tradução nossa). 
undetermined sentences have an implicit argument operating on some contextual parameters such as time, location, agent, and possible world" (CORAZZA, 2004, p.73) ${ }^{11}$. Conforme vimos, o predicado 'estar atrasado', por seu turno, não necessita desse tipo de complemento semântico.

Semelhantemente ao ponto de vista de Corazza (2004), Taylor (2001) afirma que o verbo 'chover' tem um argumento de lugar lexicalmente especificado que é $\theta$-marcado como tema. Do ponto de vista sintático, os parâmetros lexicalmente especificados são subconstituintes ao invés de constituintes. No entanto, apesar de os subconstituintes não precisarem estar expressos como constituintes no nível da sentença, eles "exigem" a atribuição de um valor fornecido contextualmente. Assim, embora uma sentença como (16) apresente todos os constituintes sintaticamente exigidos, ela é semanticamente incompleta.

The semantic incompleteness is manifest to us as a felt inability to evaluate the truth value of an utterance [(16)] in the absence of a contextually provided location (or range of locations). This felt need for a contextually provided location has its source, I claim, in our tacit cognition of the syntactically unexpressed argument place of the verb 'to rain'. (TAYLOR, 2001, p.53) ${ }^{12}$

Em suma, Corazza (2004) trabalha com sentenças meteorológicas que são interpretadas sem a construção de contextos como o do meteorologista de Recanati (2002), e assim estabelece as condições de verdade dessas sentenças sugerindo que, em 'Tá chovendo', o predicado tem duas posições argumentais - uma para o tempo (argumento fornecido pelo tempo do verbo) e outra para a localização. Assim sendo, a localização é uma exigência do predicado 'chover', e por isso, é um fenômeno semântico.

\subsection{Abordagem indexical}

Conforme vimos nas seções anteriores, Recanati (2002, 2007) e Corazza (2004) escolhem modos diferentes de explorar as sentenças meteorológicas e, talvez por isso, defendam concepções opostas sobre esse tipo de sentença. Nesta seção, apresentaremos uma terceira possibilidade - a abordagem indexical - que difere das anteriores, e argumentaremos na seção 3 que é essa abordagem que leva, caso seja aceita, aos monstros espaciais.

A abordagem indexical sugere que verbos como 'chover', encontrados em sentenças como 'Tá chovendo', são indexicais, i.e., esses itens, quando são proferidos, precisam se fixar em um contexto para serem interpretados - dito de

11 “[...] sentenças semanticamente indeterminadas têm um argumento implícito operando sobre alguns parâmetros contextuais, tais como tempo, localização, agente e mundo possível" (Tradução nossa).

12 “A incompletude semântica se manifesta para nós como uma incapacidade sentida em avaliar o valor de verdade de um proferimento [(16)] na ausência de uma localização contextualmente fornecida (ou uma série de localizações). A necessidade de uma localização contextualmente fornecida tem a sua origem, eu afirmo, em nossa cognição tácita do argumento de lugar do verbo "chover" não expresso sintaticamente. "(Tradução nossa). 
outra maneira, sem o estabelecimento de um contexto (conforme definiremos na seção 2), sentenças com verbos meteorológicos, como de resto todas as sentenças com indexicais, não expressam proposições. Sendo assim, quando esse tipo de sentença é proferida, é necessário que as coordenadas do contexto, como a localização, o tempo e o mundo possível sejam preenchidas. Considere (19) e a paráfrase em (20).

(19) Tá chovendo! $!^{13}$

(20) Está chovendo no local e no momento em que o falante profere a sentença.

Como podemos notar, as informações contextuais como a localização e o momento em que a chuva ocorre são importantes para a interpretação da sentença (19) e, por isso, aparecem na paráfrase em (20). Se fosse de outra maneira, teríamos uma paráfrase como (21) que certamente não é adequada à interpretação que temos.

(21) Está chovendo em algum lugar e em algum momento.

(21) é inadequada porque não há a determinação das informações contextuais responsáveis pelo valor semântico da sentença (19). Sendo assim, é correto dizer que nas sentenças meteorológicas há informações implícitas que necessitam do contexto para receberem um valor semântico.

É importante notar que, na abordagem indexical, as informações exigidas do contexto são semânticas no sentido de que, sem essas informações, não há proposição sendo expressa. Logo, se considerarmos que as informações quanto à localização do evento de chuva relacionam-se ao predicado 'chover', considerado um indexical, concluiremos que as informações de localização e de tempo são solicitadas nas condições de verdade da sentença, e que, sem tais informações, não há proposição sendo expressa.

Considere novamente a sentença (19), que foi proferida pela Maria em Porto Alegre, no dia 20 de junho de 2012, quando ligava para sua irmã em Florianópolis, e as condições de verdade dessa sentença em (22).

(22) 'Tá chovendo' expressa uma proposição verdadeira sse estar chovendo é o caso em Porto Alegre no dia 20 de junho de 2012 no mundo $\mathrm{w}^{* 14}$.

A paráfrase adequada à interpretação da irmã de Maria para a sentença (19), proferida pela Maria, é a seguinte:

\footnotetext{
${ }^{13}$ Se não houver nenhum contexto associado à (19), podemos dizer que não há proposição sendo expressa, mas apenas um caráter como veremos na seção 2. A ideia é que (19) sem a informação de lugar é o mesmo que encontrarmos um bilhete com os dizeres 'Eu estou com fome' sem sabermos quem escreveu o bilhete; sabemos algo sobre o que está expresso, mas não estaremos de posse de uma proposição.

${ }^{14}$ Neste caso, o asterisco indica que o mundo (w) é o mundo do proferimento da sentença.
} 
(23) Está chovendo em Porto Alegre no dia 20 de junho de 2012.

(23) mostra que as informações contextuais no proferimento das sentenças meteorológicas são necessárias à interpretação. Mais do que isso, o estabelecimento das condições de verdade em (22) indica que as informações da localização e do tempo do contexto são cruciais para a atribuição do valor semântico das sentenças meteorológicas e por isso são aspectos semânticos.

Em suma, segundo a abordagem indexical, através do estabelecimento das condições de verdade das sentenças com predicados meteorológicos, notamos que o preenchimento da coordenada de localização (além da coordenada de tempo e de mundo possível) é uma exigência do verbo 'chover', e é por esse motivo que ele pode ser considerado indexical. Por conta dessas ideias, a abordagem indexical está mais próxima da abordagem defendida por Corazza (2004). No entanto, há uma diferença importante entre elas: enquanto Corazza (2004) afirma que a localização é um argumento implícito dos predicados meteorológicos, a abordagem indexical dirá que o item lexical 'chover' (e os demais verbos meteorológicos) só pode expressar uma proposição segundo um contexto, e essa característica não envolve uma posição argumental. Porém, só é possível explicitarmos essa abordagem de posse de uma teoria sobre indexicais e é isso que apresentaremos na próxima seção.

\section{TEORIA PARA OS INDEXICAIS PROPOSTA POR KAPLAN}

As expressões indexicais ${ }^{15}$ são um grupo de palavras que incluem pronomes pessoais e possessivos ('eu', 'meu', 'você', 'ele'e 'dele'), demonstrativos ('aquele'; 'este' e 'esse'), advérbios ('aqui', 'agora' e 'amanhã'), adjetivos ('real' e 'atual'), e ainda os morfemas temporais dos verbos. Todos esses termos compartilham uma característica: necessitam de informações contextuais para receberem um valor semântico. Sendo assim, se essas expressões não são fixadas em um contexto, elas não recebem um valor semântico.

David Kaplan propôs a primeira grande análise semântico-formal para os indexicais no artigo Demonstratives, publicado em 1989. Para isso, o filósofo muniu-se da semântica de mundos possíveis e do conceito de designador rígido de Kripke (1980). Baseado na ideia de designador rígido, Kaplan propôs que os indexicais são termos diretamente referenciais, ou seja, termos que se referem a um dado objeto sem nenhum tipo de mediação, e se referem a esse mesmo objeto em todos os mundos possíveis em que esse objeto existe. Considere (24), com o indexical 'eu':

${ }^{15}$ Usaremos o termo "indexical”, que, segundo Chierchia e McConnell-Ginet (1990, p.265), está etimologicamente ligado ao vocábulo grego que significa indicação ou apontamento, ao invés de "indicial" e "dêítico". Reservaremos o termo "dêitico" para certos usos que fazemos de alguns itens linguísticos, por exemplo, podemos ter usos dêiticos de descrições definidas como 'o presidente do Brasil' (junto com um apontamento); o termo "indicial" remete a qualquer item que deve ser interpretado em relação a algum índice ou parâmetro (mundo possível, tempo, etc.), como 'possivelmente' e 'sempre'; "indexical” remete às expressões que recebem valor semântico em função de um contexto, conforme definiremos na sequência. 
(24) $E u$ poderia estar morto,

se o falante do contexto c (o contexto de proferimento de (24)) é Pelé, Pelé será tomado como o referente de 'eu' em todos os mundos possíveis acessíveis a partir (do mundo) de c. Assim, a sentença (24) em c será considerada verdadeira se e somente se em algum mundo possível w, o indivíduo denotado por 'eu' em c (Pelé) está morto. No entanto, mesmo se o falante de 'eu' não existir no mundo w, 'eu' ainda denota o mesmo indivíduo, pois a referência de 'eu' é estabelecida no contexto de proferimento (c) e não no mundo de avaliação (w). A ideia, grosso modo, é que indexicais envolvem um contexto para determinar seu valor (referente), já proposições envolvem mundos possíveis para determinar seu valor (verdadeiro ou falso).

Outro aspecto importante a se notar sobre os indexicais está relacionado às sentenças verdadeiras a priori, como é o caso de 'Eu estou aqui'. Não precisamos saber nada sobre o mundo para sabermos que ela é sempre verdadeira. No entanto, se considerarmos essa sentença num contexto configurado como áPelé, campo do Santosñ, ela expressaria algo como 'Pelé está no campo do Santos', que é verdadeiro somente se soubermos algo sobre o mundo, ou seja, a sentença é verdadeira somente a posteriori (i.e., é uma sentença contingente).

Devido a esse tipo de comportamento, Kaplan propõe dois passos para a determinação do significado das expressões linguísticas, as funções caráter e conteúdo.

Antes de verificar como as funções caráter e conteúdo são aplicadas, precisamos entender o que é e como é formado o contexto para Kaplan (1989). O contexto é formado por um conjunto de coordenadas que podem ser representadas através de uma ênupla como ác, $c_{\mathrm{a}}, \mathrm{c}_{\mathrm{h}}, \mathrm{c}_{\mathrm{t}}, \mathrm{c}_{1}, \mathrm{c}_{\mathrm{w}} \tilde{\mathrm{n}}^{16}$, em que "c $\mathrm{c}_{\mathrm{a}}$ " está por "agente do contexto c", "c $\mathrm{c}_{\mathrm{h}}$ " por "ouvinte do contexto c", "c $\mathrm{c}_{\mathrm{t}}$ " por "tempo do contexto c", "c $\mathrm{c}_{1}$ " por "lugar do contexto c" e "c $\mathrm{w}_{\mathrm{w}}$ " por "mundo do contexto c"; somente a partir dessa ênupla determinada é que chegamos ao caráter e ao conteúdo. Além disso, é preciso ressaltar que para Kaplan o contexto relevante para o estabelecimento da referência dos indexicais é sempre o contexto de proferimento, que notaremos como c*.

O caráter é uma função que toma como input um dado contexto e produz como output um conteúdo; podemos entender o caráter como o valor pré-proposicional de um enunciado num dado contexto. Por sua vez, o conteúdo toma como input um mundo possível e produz um valor semântico: o conteúdo é o valor proposicional.

Considerando (26) e estabelecendo como contexto de proferimento $\mathrm{c}^{*}=\mathrm{ác}_{\mathrm{a}}=$ Pelé, $\mathrm{c}_{\mathrm{h}}=$ Edinho, $\mathrm{c}_{\mathrm{t}}=2012, \mathrm{c}_{\mathrm{l}}=$ campo do Santos, $\mathrm{c}_{\mathrm{w}}=\mathrm{w}^{* 17} \tilde{\mathrm{n}}$, chegaremos ao caráter e ao conteúdo a seguir:

\footnotetext{
${ }^{16}$ Essa ênupla pode ser aumentada para incluir objetos presentes no contexto para dar conta dos demonstrativos.

${ }^{17} \mathrm{O}$ asterisco sobrescrito em $\mathrm{w}$ faz referência ao mundo que habitamos, e c* faz referência ao contexto de proferimento. Fazemos a assunção simplificadora de que o mundo do contexto de proferimento $\left(\mathrm{c}_{\mathrm{w}}\right)$ é o mundo em que o falante está; dito de outra forma, se não houver necessidade do contrário, assumiremos que o mundo em que a sentença é avaliada (i.e., o mundo possível usado no conteúdo) é o mundo do contexto (i.e., $\mathrm{c}_{\mathrm{w}}$ ). Desse modo, avaliamos as condições de verdade de uma sentença, em princípio, em relação a um contexto e em relação ao mundo desse contexto.
} 
(26) $\mathrm{S}=E u$ estou aqui

(27) Caráter $(\mathrm{S})=\lambda \mathrm{c} \lambda \mathrm{w}\left[\mathrm{c}_{\mathrm{a}}\right.$ está em $\left.\mathrm{c}_{1}\right]\left(\mathrm{c}^{*}\right)$

(28) Conteúdo $(\mathrm{S})=$ Caráter $(\mathrm{S}) \lambda \mathrm{c} \lambda \mathrm{w}\left[\mathrm{c}_{\mathrm{a}}\right.$ está em $\left.\mathrm{c}_{1}\right]\left(\mathrm{c}^{*}\right)\left(\mathrm{w}^{*}\right)$

Conteúdo $(\mathrm{S})=$ Caráter $(\mathrm{S}) \lambda \mathrm{w}\left[\mathrm{c}_{\mathrm{a}}\right.$ está em $\left.\mathrm{c}_{1}\right]\left(\mathrm{w}^{*}\right)$

Conteúdo $(\mathrm{S})=\lambda \mathrm{w}$ [Pelé está no campo do Santos] $\left(\mathrm{w}^{*}\right)$

Segundo a definição dada anteriormente, o caráter de (26) é igual ao agente do contexto estar na localização do contexto. No entanto, para que determinemos o significado completo, falta definir o conteúdo, que é uma função que toma um mundo possível e produz um valor semântico - assumimos que o mundo a ser considerado é o mundo do contexto $\mathrm{c}_{\mathrm{w}}\left(\mathrm{w}^{*}\right)$. Assim sendo, o conteúdo de (26) é o caráter (o agente do contexto estar na localização do contexto) em relação a um mundo possível, o que vai gerar um valor semântico (nesse caso, um valor de verdade): o conteúdo de (26), no contexto c*, é o conjunto de mundos em que Pelé está no campo do Santos.

De acordo com Kaplan (1989), operadores podem manipular o conteúdo de um indexical; esse é o caso de operadores modais, como 'possivelmente' e 'necessariamente'. Considere a sentença ' $\mathrm{S}=$ Necessariamente $\mathrm{eu}$ estou aqui', que é verdadeira sse em todos os mundos possíveis $\mathrm{w}$ ' acessíveis a partir de $\mathrm{c}_{\mathrm{w}}, \mathrm{c}_{\mathrm{a}}$ (o agente) está em c (o lugar do contexto). Se aplicarmos c* (já definido acima) a essa sentença, o resultado é, grosso modo, 'Necessariamente, Pelé está no campo do Santos'; uma sentença que é verdadeira sse em todos os mundos possíveis w', acessíveis a partir de $\mathrm{c}_{\mathrm{w}}$, Pelé está no campo do Santos. Sendo assim, 'S = Necessariamente eu estou $a q u i$ ', diferentemente de ' $\mathrm{S}=E u$ estou $a q u i$ ', e de acordo com nossa intuição e com a teoria, não é verdadeira a priori.

Se, de um lado, segundo o autor, operadores podem manipular o conteúdo de um indexical, de outro, não há operadores que atuam sobre o caráter de um indexical em língua natural ${ }^{18}$.

Em suma, a teoria clássica para os indexicais faz duas afirmações importantes para os objetivos deste artigo: (i) não existem operadores que controlam o caráter dos indexicais, especificamente, operadores que controlam o contexto em que os indexicais são avaliados; e (ii) os indexicais só podem ser fixados no contexto de proferimento $\left(\mathrm{c}^{*}\right)$. Essas afirmações são refutadas por autores como Schlenker (2003, 2010), que apresenta dados do amárico e do inglês mostrando que há operadores que controlam o caráter dos indexicais e indexicais sendo avaliados em outro contexto nessas línguas; e ainda, Basso e Teixeira (2011) e Teixeira (2012), que apresentam dados sugerindo que existem operadores-monstros e indexicais avaliados em contextos diferentes de $\mathrm{c}^{*}$ no PB. Os principais aspectos dessas refutações serão apresentados nas seções seguintes.

18 Kaplan aceita que em linguagens formais operadores-monstros (como denominou os operadores capazes de modificar o contexto de avaliação dos indexicais) podem ser construídos e adicionados, mas nega sua existência em línguas naturais. Logo, teríamos em língua natural, segundo a teoria kaplaniana, apenas operadores modais, aqueles que, nos termos de Kaplan, têm escopo sobre o conteúdo e as circunstâncias de avaliação (mundos possíveis). 


\subsection{Operadores-monstros}

Segundo Schlenker (1999, 2003, 2010), há operadores em línguas naturais que atuam sobre o contexto de fixação dos indexicais, ou seja, há operadoresmonstros que podem modificar o caráter dos indexicais em seu escopo. Para comprovar isso, o autor reúne dados do inglês e do amárico que mostram que a proibição da existência de operadores-monstros e indexicais monstruosos feita por Kaplan (1989) está equivocada.

$\mathrm{Na}$ argumentação contra a teoria de Kaplan (1989), Schlenker propõe que o verbo de atitude, presente num relato de proferimento ou de pensamento, controla uma variável de contexto e, por isso, pode fixar a referência dos indexicais que aparecem sob seu escopo. Assim sendo, um indexical pode depender do contexto de proferimento $\left(\mathrm{c}^{*}\right)$ ou do contexto reportado ( $\left.\mathrm{c}^{\prime}\right)$; esse tipo de comportamento caracteriza os verbos de atitude e os verbos de dizer como operadores-monstros. Vejamos o exemplo abaixo, do amárico:

(29) Situação: João disse: "Eu sou um herói”.

(30) João Jägna näNN yt-lall

(31) João herói eu-sou dizer-3 ${ }^{a}$ sg.m

(32) ? João $o_{i}$ disse que eu $u_{i}$ sou um herói.

A situação em (29) é relatada em amárico com o uso do indexical de primeira pessoa (nä), que podemos observar em (30). Nesse caso, 'nä' está sendo avaliado a partir do contexto que está sendo relatado (c'), pois como Schlenker (2003, p. 32) indica, a fórmula lógica da sentença do amárico é: "SAY á ${ }_{\text {aJohn, now actuallyñ }} \mathrm{c}_{\mathrm{i}}$ be-a-hero $\left(\operatorname{agente}\left(\mathrm{c}_{\mathrm{i}}\right)\right.$, time $\left(\mathrm{c}_{\mathrm{i}}\right)$, world $\left.\left(\mathrm{c}_{\mathrm{i}}\right)\right)$ ", na qual $\mathrm{c}_{\mathrm{i}}$ é o contexto que está sendo relatado. Levando em conta a fórmula lógica da sentença do amárico, se traduzíssemos (30) para o PB, teríamos algo como (32). Nesse caso, note que o item 'João', à esquerda do verbo dicendi, seria fixado no contexto $\mathrm{c}^{*}$; por sua vez, os itens à direita do verbo de dizer (principalmente o indexical) receberiam valor semântico a partir do contexto c', i.e., o indexical teria como referente o João (falante do contexto que está sendo relatado) e não o falante do contexto de proferimento. Usando uma sentença do $\mathrm{PB}$, o relato de uma situação como (29) seria feito com a sentença dada em (33), em que há um elemento anafórico retomando João. Nesse caso, a sentença e o pronome 'ele' recebem seu valor semântico a partir do contexto $\mathrm{c}^{*} \mathrm{e}$ não há mudança no contexto.

(33) O João disse que ele $e_{i}$ é um herói.

A partir de dados como esse, Schlenker postula que verbos de atitude e verbos dicendi $i^{19}$ são operadores-monstros, pois podem controlar o contexto em que os indexicais são avaliados.

19 Schlenker afirma que os verbos de atitude são monstros. No entanto, também utiliza exemplos de sentenças com verbos dicendi, mudando o contexto de avaliação dos indexicais. Para evitar um comprometimento teórico, discriminamos os grupos de verbos - verbos de atitude e verbos de dizer - sem assumir a posição de Schlenker. 
A seguir, a Figura $1^{20}$ descreve como se dá a dependência contextual dos indexicais nas sentenças subordinadas, ou sentenças de relato, em que um verbo de atitude vem seguido por indexicais que podem ser monstruosos ou não. Vemos que o indexical 'nä'21 do amárico pode depender tanto do contexto de proferimento, representado pela ênupla em letras maiúsculas, quanto do contexto reportado, representado em minúsculas, quando está sob o escopo do operador de atitude. O indexical do inglês 'I', por exemplo, só pode ter seu valor determinado a partir do contexto de proferimento, estando ou não sob o escopo do operador de atitude, ou seja, é um indexical que respeita os pressupostos da teoria de Kaplan (1989).

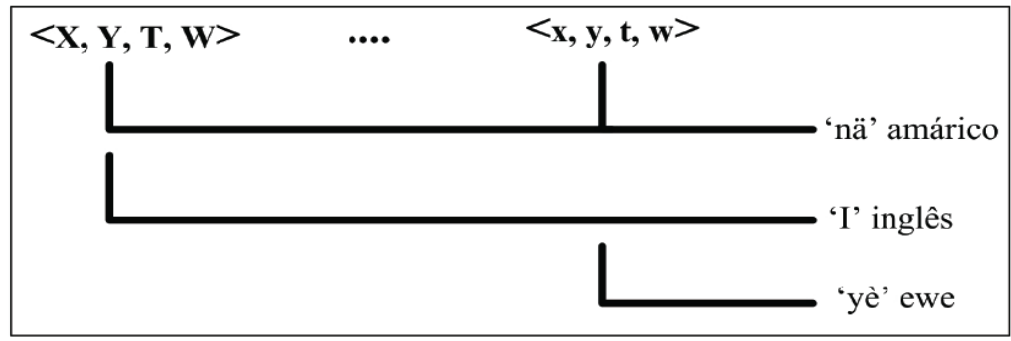

Figura 1: Fixação dos Indexicais ao Contexto ${ }^{22}$.

Schlenker (2003, 2010) estabelece quatro critérios para que indexicais sejam considerados monstruosos: (i) o elemento deve ser semanticamente dependente do contexto; (ii) o elemento deve ser um indexical lexicalmente especificado como dependente do contexto; (iii) deve-se excluir a possibilidade de que a oração encaixada (após o verbo de atitude ou verbo de dizer) esteja sendo citada, i.e., excluem-se casos de discurso direto (total ou parcial); e (iv) o elemento investigado deve ser interpretado de se quando é avaliado a partir do contexto mudado ${ }^{23}$.

Esses critérios também foram usados em análises de dados do PB em Basso \& Teixeira (2011) e Teixeira (2012). Alguns dos dados desse último trabalho serão apresentados na sequência.

Teixeira (2012) analisa o comportamento das expressões temporais 'em dois dias', 'o dia depois de amanhã', 'o dia antes de ontem', 'dois dias atrás' em duas configurações diferentes: dentro e fora do escopo do operador de atitude. Considere essas expressões fora do escopo do operador de atitude em (34) a (37).

${ }^{20}$ Esquema de fixação dos indexicais ao contexto cf. Schlenker (1999, p.13).

${ }^{21}$ No amárico, quando há um verbo de atitude (AT), o indexical que é avaliado em um contexto mudado (c') tem a mesma morfologia do item que é avaliado no contexto de proferimento (c*).

${ }^{22} \mathrm{Na}$ terceira linha da Figura 1 está representada a relação de um pronome logofórico do ewe (yè) com o contexto. Esse tipo de termo indexical, diferente dos demais, só pode receber um valor semântico do contexto que está sendo relatado (c'), quando está sob o escopo de um operador de atitude. Os pronomes logofóricos não serão abordados neste texto.

${ }^{23}$ Note que os quatro critérios estabelecidos por Schlenker $(2003,2010)$ formam dois grupos: os critérios de (i) a (iii) são exigidos por todas as línguas naturais que possuem indexicais sendo avaliados em contextos mudados, independentes da teoria considerada. No entanto, o critério (iv) não é uma exigência das línguas naturais e sim da teoria de Schlenker (2003, 2010) e dos que compartilham dela. 
Cadernos de ESTUDOS LINGǘĺsTICOS (55.2) - Jul./Dez. 2013

(34) As pessoas que realizaram exames dois dias atrás devem retornar ao laboratório.

(35) As pessoas que realizaram exames no dia antes de ontem devem retornar ao laboratório

(36) A reunião dos pais acontecerá em dois dias.

(37) A reunião dos pais acontecerá no dia depois de amanhã.

Como podemos notar, todas as expressões temporais são dependentes do contexto, pois, ao determinarmos o dia em que são proferidas, também determinamos os dias a que as expressões temporais se referem. Sendo assim, especificar o contexto de produção das sentenças é crucial para que sejam estabelecidos os valores semânticos das expressões temporais. Por exemplo, se João proferir a sentença (34) numa quarta-feira, o referente da expressão ‘dois dias atrás' será calculado a partir do dia do proferimento do João (quarta-feira), o que nos leva à segundafeira. Sendo assim, o referente da sentença em (34) é determinado a partir do tempo do contexto de proferimento $\left(\mathrm{c}_{\mathrm{t}}^{*}\right)$. Como é esperado, isso se dá com todas as sentenças de (34) a (37). A única diferença entre as sentenças, até aqui, é a orientação temporal.

Vejamos agora essas mesmas expressões sob o escopo de um operador de atitude. Nessa configuração, notaremos que há indexicais kaplanianos, que só podem ser avaliados no contexto de proferimento $\left(\mathrm{c}^{*}\right)$, e há indexicais monstruosos ou modificados, que podem ter seu contexto de avaliação modificado pelo operador de atitude. Considere (38) e (39), que possuem indexicais temporais kaplanianos ou bem-comportados.

(38) O João tem me dito repetidamente, ao longo dos anos, que devolverá meu dinheiro no dia depois de amanhã.

(39) ? O João tem me dito repetidamente, ao longo dos anos, que estava doente no dia antes de ontem.

A avaliação desses indexicais sempre se dá em relação ao contexto c* e, por isso, não há mudança no seu contexto de fixação. Para (38), a interpretação fica mais clara quando usamos datas: se eu proferir (38) em 03 de julho de 2012, o ouvinte preencherá o conteúdo do indexical 'no dia depois de amanhã' com 05 de julho de 2012, porque ele toma como ponto de partida o tempo c* ${ }_{\text {t }}$, dia 03 de julho de 2012 (dia do meu proferimento). Desse modo, o que João vem me dizendo todos os anos é algo como 'Eu devolverei o teu dinheiro em 05 de julho de 2012'.

Segundo Teixeira (2012), a sentença em (39) é estranha do ponto de vista semântico porque a expressão indexical 'no dia antes de ontem' só pode ser avaliada em relação ao momento do proferimento $\left(\mathrm{c}_{\mathrm{t}}^{*}\right)$. Assim, essa interpretação entra em contradição com a leitura do item 'repetidamente', já que ele dá a ideia de que os proferimentos (reiterados) se deram em contextos diferentes de c*. Esse comportamento indica que 'no dia antes de ontem', assim como 'no dia depois de amanhã', só pode ser avaliado adequadamente quando se refere à coordenada de tempo do contexto de proferimento. 
Agora vamos analisar as sentenças (40) e (41) com indexicais monstruosos após o verbo dicendi .

(40) O João tem me dito repetidamente, ao longo dos anos, que devolverá meu dinheiro em dois dias.

(41) O João tem me dito repetidamente, ao longo dos anos, que ele estava doente dois dias atrás.

Nessas sentenças, as expressões indexicais temporais são avaliadas em relação ao tempo do contexto reportado (c'), i.e., em relação aos vários proferimentos do João, o falante de c' e, por isso, o verbo de dizer é um monstro que muda o contexto de avaliação dos indexicais.

Para (40), o que o João vem falando durante os anos é algo como 'Eu devolverei teu dinheiro em dois dias'; a expressão 'em dois dias', usada no meu proferimento em (42), não se refere à coordenada de tempo do contexto do meu proferimento $\left(\mathrm{c}^{*} \mathrm{t}\right)$. Na verdade, ela se refere à coordenada de tempo do contexto reportado por mim (c').

Da mesma forma, em (41), o indexical ‘dois dias atrás' também é avaliado em relação aos vários contextos reportados e em relação ao tempo desses contextos $\left(c^{\prime}{ }_{t}\right)$. E, por isso, 'dois dias atrás' recebe seu valor semântico em relação aos vários proferimentos de João, que é o falante do contexto reportado (c'). Assim, o que o João vem dizendo todos os anos é algo como 'Eu estava doente dois dias atrás'.

Portanto, Teixeira (2012), após a análise das expressões temporais do PB, conclui que 'em dois dias' e 'dois dias atrás' são indexicais monstruosos após o verbo dicendi, já que há mudança no contexto considerado, input da função caráter $^{24}$. Por isso, o verbo dicendi é um operador-monstro. Na Figura 2, a seguir, apresentamos o resumo dos seus achados no PB em relação aos critérios de Schlenker que vimos na seção 2: os indexicais kaplanianos receberam ' $\mathrm{OK}$ ' para os critérios (i), (ii) e (iii), só não se adequaram ao critério (iv), já que não podem ser interpretados de se em relação ao tempo; os indexicais monstruosos receberam 'OK' para todos os critérios.

\begin{tabular}{|l|c|c|}
\hline \multicolumn{1}{|c|}{ Critérios } & \multicolumn{1}{|c|}{$\begin{array}{c}\text { dois dias atrás } \\
\text { em dois dias }\end{array}$} & $\begin{array}{c}\text { o dia antes de ontem } \\
\text { o dia depois de amanhã }\end{array}$ \\
\hline (i) dependente do contexto & OK & OK \\
\hline (ii) indexical estrito & OK & OK \\
\hline (iii) não ser citado & OK & OK \\
\hline (iv) interpretado de se & OK & Não \\
\hline & indexical monstruoso & indexical kaplaniano \\
\hline
\end{tabular}

Figura 2: Indexicais Modificados do PB.

\footnotetext{
${ }^{24}$ Essas expressões devem ser interpretadas de se (o tempo deve ser avaliado a partir do tempo do proferimento do João $\left(c^{\prime}\right)$ ), o que faz com que as expressões não se refiram à coordenada de tempo do meu proferimento $\left(\mathrm{c}_{\mathrm{t}}^{*}\right)$, e sim à coordenada de tempo do contexto reportado por mim $\left(\mathrm{c}_{\mathrm{t}}\right.$ ).
} 


\section{OPERADORES-MONSTROS ESPACIAIS}

Nesta seção faremos algumas considerações que envolvem os indexicais espaciais, i.e., indexicais que representam a localização do contexto $\left(c_{1}\right)$. Com isso procuramos responder a uma das questões que trata da busca de operadoresmonstros e indexicais monstruosos levando em conta a concepção abordada na seção 1.3, em que um proferimento de uma sentença meteorológica exige uma coordenada de localização, mesmo sem ela estar realizada foneticamente. Em outras palavras, baseados na concepção da Abordagem Indexical, que sugere que um predicado como 'chover' é indexical e que, por isso, precisa que as coordenadas de localização, entre outras, sejam preenchidas, partimos em busca de monstros em proferimentos meteorológicos, já que a coordenada de localização assume grande importância para a interpretação dos proferimentos meteorológicos, apesar de nem sempre estar expressa linguisticamente.

No domínio espacial, procuramos por expressões indexicais que, após um operador de atitude, mais especificamente um verbo dicendi, possam ter seu contexto de avaliação modificado, e assim recebam seu valor semântico a partir do contexto reportado e não do contexto de proferimento. Esse tipo de indexical, contudo, é diferente da maioria dos indexicais analisados, pois acreditamos que em algumas sentenças que tratam de fenômenos da natureza, especialmente, mas não exclusivamente, o indexical de localização não esteja explícito, apesar de ser determinante para a interpretação.

Segundo Chierchia e McConnel-Ginet, quando uma sentença como 'Tá chovendo' é proferida, a sentença é '[...] understood as localized to a region centered on the place in which the sentence is produced. That is, [ela] is generally interpreted as synonymous with [(42)], which contains an overt occorrence of the indexical here"25 (1990, p.266), ao invés de ser avaliada em relação à qualquer local do globo terrestre. Em vista disso, considere (42).

\section{(42) Tá chovendo aqui.}

'Tá chovendo' e (42) são, em princípio, sinônimas, mas (42) é mais "verborrágica" que 'Tá chovendo' e, portanto, dispara implicaturas pragmáticas (por que um falante cooperativo falaria (42), que é mais longa e diz a mesma coisa, se ele tem à disposição a sentença 'Tá chovendo'?). Uma resposta possível é que com (42) sempre reforçamos a interpretação de lugar, ou seja, podemos usar (42) para falar de uma goteira (quando dizemos, dentro de casa, 'tá chovendo aqui', nos referimos ao cômodo em que estamos, por exemplo, e não à cidade em que estamos; não é possível, contudo, usar 'Tá chovendo' para falar da goteira). Essa especialização pragmática explica a possibilidade de termos 'Tá chovendo' e (42) como sinônimas, mas com usos próprios.

25 “[...] entendida como localizada em relação a uma região centrada no lugar em que a sentença é produzida. Isto é, [ela] é geralmente interpretada como sinônimo de [(42)], que contém uma ocorrência explícita do indexical aqui” (Tradução nossa). 
Trazemos essa pequena discussão, pois os fatos apontados por Chierchia e McConnel-Ginet (1990) mostram que é possível considerar que uma sentença proferida (como (42)) sempre traz informações sobre a localização do contexto em que ocorre o proferimento, embora o indexical de localização possa estar implícito. Partindo desse raciocínio, ou seja, de que é possível que encontremos indexicais espaciais tanto implícitos quanto explícitos nos proferimentos, não é impossível que também encontremos indexicais espaciais monstruosos nessas mesmas condições.

Mas antes de entrar na discussão sobre monstros espaciais, vamos analisar a sentença 'Tá chovendo', nos moldes da Abordagem Indexical a partir da teoria de Kaplan (1989), ou seja, definindo o seu caráter e seu conteúdo, em relação ao seguinte contexto de proferimento $\mathrm{c}^{*}=\mathrm{a}_{\mathrm{a}}=\mathrm{J}_{\mathrm{a}} \mathrm{a} \mathrm{,}, \mathrm{c}_{\mathrm{h}}=$ Pedro, $\mathrm{c}_{\mathrm{t}}=14 \mathrm{~h}, \mathrm{c}_{1}=$ Porto Alegre, $\mathrm{c}_{\mathrm{w}}=\mathrm{w}^{*} \tilde{\mathrm{n}}$. Considere (43):

(43) $\mathrm{S}=$ Tá chovendo

(44) Caráter $(\mathrm{S})=\lambda \mathrm{c} \lambda \mathrm{w}\left[\right.$ chove em $\mathrm{c}_{\mathrm{t}}$ em c $\left.\mathrm{c}_{1}\right]\left(\mathrm{c}^{*}\right)$

(45) Conteúdo $(\mathrm{S})=$ Caráter $(\mathrm{S}) \lambda \mathrm{c} \lambda \mathrm{w}\left[\right.$ chove em $\mathrm{c}_{\mathrm{t}}$ em $\left.\mathrm{c}_{1}\right]\left(\mathrm{c}^{*}\right)\left(\mathrm{w}^{*}\right)$

Conteúdo $(\mathrm{S})=$ Caráter $(\mathrm{S}) \lambda \mathrm{w}\left[\right.$ chove em $\left.\mathrm{c}_{\mathrm{t}} \mathrm{em} \mathrm{c}_{1}\right]\left(\mathrm{w}^{*}\right)$

Conteúdo $(\mathrm{S})=\lambda \mathrm{w}\left[\right.$ chove agora $(14 \mathrm{~h})^{26}$ em (Porto Alegre) $]\left(\mathrm{w}^{*}\right)$

Agora considere a sentença em (46), que segue os moldes das sentenças com indexicais temporais monstruosos encontradas no PB em Teixeira (2012), ou seja, uma sentença em que há um verbo de dizer que pode ser um operador-monstro em determinadas situações.

(46) O João tem me dito, toda vez que me liga de Porto Alegre, que tá chovendo.

Uma sentença como (46) gera uma interpretação que pode ser parafraseada adequadamente por (47), mas não por (48), nem por (49).

(47) O João tem me dito, toda vez que me liga de Porto Alegre, que tá chovendo em Porto Alegre.

(48) O João tem me dito, toda vez que me liga de Porto Alegre, que tá chovendo em Florianópolis.

(49) O João tem me dito, toda vez que me liga de Porto Alegre, que tá chovendo em qualquer parte do planeta.

Se de fato o verbo 'chover' é um indexical que exige informação de localização (i.e., lugar do contexto, ou c), então (46) deve ser avaliada em relação ao contexto reportado, ou seja, em relação aos proferimentos feitos pelo João ao telefone, o que temos é um indexical espacial monstruoso. Assim sendo, o predicado ou verbo 'chover', que é indexical, está sob o escopo do operador de atitude e por isso deve ser avaliado em relação ao local do contexto reportado ( ${ }^{\prime}{ }_{1}=$ Porto Alegre), e não em relação ao contexto de proferimento $\left(\mathrm{c}^{*}{ }_{1}=\right.$ Florianópolis $)$.

\footnotetext{
${ }^{26}$ Consideraremos o gerúndio como expressando o presente semântico.
} 
Um exemplo bem mais trivial pode ser encontrado na seguinte conversa: João e Maria estão em São Carlos e Pedro está de férias em Antofagasta. Pedro liga para o casal e conversa com Maria por telefone; ao fim da conversa, João pergunta à Maria o que o Pedro disse, e ela responde: "O Pedro falou que tá chovendo". Ora, a paráfrase adequada para essa sentença envolve Antofagasta e não São Carlos; portanto, se 'chover' for um indexical, temos evidência de que 'falar que' é um operador-monstro, conforme representado a seguir:

(50) [O Pedro falou que]c* [tá chovendo]c',

pois a primeira parte da sentença é avaliada em relação à localização do contexto de proferimento ( $\mathrm{c}_{1}^{*}=$ São Carlos) e 'tá chovendo' é avaliado em um contexto diferente, i.e., na localização do contexto relatado $\left(c_{1}{ }^{\prime}=\right.$ Antofagasta $)$.

Se isso estiver correto podemos afirmar que o verbo de dizer é um monstro que pode mudar o contexto em que a localização de 'tá chovendo' é determinada. Assim, a interpretação do indexical, e por isso a localização relevante para a interpretação, se dá a partir da localização do agente do contexto reportado, ou seja, do Pedro, o que nos conduz ao monstro espacial.

As considerações feitas nesta seção nos levam a afirmar que 'chover' pode ter a sua coordenada de localização avaliada em um contexto modificado quando está sob o escopo de um verbo dicendi. Sendo assim, o verbo de dizer é um operadormonstro no PB e a localização de 'tá chovendo' recebe seu valor a partir do local do contexto relatado $\left(\mathrm{c}^{\prime}\right)$ e não a partir do local do contexto de proferimento $\left(\mathrm{c}^{*}\right)$. Sendo assim, mesmo que 'chover' nem sempre tenha a coordenada de localização expressa linguisticamente, o seu papel semântico é importante, pois esse parâmetro é responsável pela fixação do local relevante do contexto, e, portanto determinante para a avaliação semântica da sentença. Logo, a partir da rápida análise feita aqui podemos dizer que 'chover', pode, quando está sob o escopo de um operador de atitude, ter a localização do contexto de avaliação mudada de c* para c' e, por isso, temos um monstro espacial no caso das sentenças meteorológicas sob o escopo do verbo dicendi.

\section{CONCLUSÃO}

As sentenças meteorológicas envolvem uma série de problemas bastante complexos que têm a ver com a questão do estabelecimento de uma proposição sem envolver necessariamente uma localização. Neste artigo, nosso objetivo não foi atacar diretamente esse problema, mas sim mostrar que uma das soluções possíveis - a Abordagem Indexical - tem algumas consequências interessantes para a teoria de indexicais formulada por Kaplan (1989), certamente uma das mais importantes abordagens sobre indexicais.

Kaplan (1989) afirmou que os indexicais são fixados exclusivamente com relação ao seu contexto de proferimento e que não é possível mobilizarmos outro contexto para a interpretação dessas expressões. Diversos autores, contudo, mostraram que essa assunção de Kaplan está equivocada, e que há em línguas 
naturais operadores que podem mudar o contexto de fixação de indexicais - os operadores-monstros.

Na literatura, é possível encontrar operadores-monstros que se relacionam com os pronomes, com o tempo e com os mundos possíveis, mas até agora não havia nenhum tratamento de, ou mesmo exemplos, de operadores-monstros que atuassem sobre a coordenada de localização do contexto. O que esperamos ter mostrado é que, uma vez aceita a Abordagem Indexical para as sentenças meteorológicas, abrem-se as portas também para operadores-monstros espaciais, fazendo com que todas as coordenados do contexto possam ser controladas por esse tipo de operador e assim refutando por completo a proibição de operadoresmonstros feita por Kaplan (1989). Além disso, a estrutura que enseja esses operadores é a mesma prevista por Schlenker (1999, 2003, 2012) e Teixeira (2012), e pode ser analisada com o mesmo ferramental teórico, não gerando, portanto, nenhum ônus teórico e eliminando a assimetria entre as coordenadas do contexto, dado que todas elas, incluindo a coordenada espacial, podem ser alvo de operadores-monstros.

\section{$\overline{\text { REFERÊNCIAS BIBLIOGRÁFICAS }}$}

BASSO, R. M.; TEIXEIRA, L. R. 2011. Monstros no discurso (meta)ficcional. Revista Letras (UFPR), v. 83: 133-162. Disponível em: <http://ojs.c3sl.ufpr.br/ojs2/index.php/letras/article/ view/21714/17329>.

CHIERCHIA, G.; MCCONNELL-GINET, S. 1990. Meaning and Grammar: an introduction to semantics. USA: MIT Press, 492 p. ( $5^{\mathrm{a}}$ ed.).

CORAZZA, E. 2004. Refecting the Mind: Indexicality and Quasi- Indexicality. New York: Oxford University Press.

KAPLAN, D. 1989. Demonstratives: An essay on the semantics, logic, metaphysics, and epistemology of demonstratives an other indexicals. In: ALMOG, J.; PERRY, J.; WETTSTEIN, H. (Ed.). Themes from Kaplan. New York: Oxford Univesity Press: 481563.

KRIPKE, S. 1980. Naming and Necessity. USA: Harvard University Press. ( $1^{\mathrm{a}}$ ed. 1972).

PERRY, J. 1993. Thoughts without Representation. In: PERRY, J. The Problem of the Essential Indexical and Other Essays. Oxford University Press: New York: 205- 226.

PREDELLI, S. 2008. Modal monsters and talk about fiction. Journal of Philosophical Logic. n. 37: 277-297.

RECANATI, F. 2002. Unarticulated constituents. Linguistics and Philosophy, v. 25: 299-345. . 2007. It is raining (somewhere). Linguist Philos. v. 30: 123-146.

SCHLENKER, P. 1999. Propositional Attitudes and Indexicality: A Cross-Categorial Approach. Tese (Doutorado) - Massachusetts Institute of Technology: USA.

2003. A plea for monsters. Linguistics and Philosophy. v. 26: 29-120.

2010. Indexicality and De Se Reports. Disponível em: <https://files.nyu.edu/pds4/public/ Schlenker-Indexicality_and_De_Se.pdf>. Acesso em: Julho de 2012. 
Cadernos de EsTUDOS LNGǘísTICOS (55.2) - Jul./Dez. 2013

TAYLOR, K. A. 2001. Sex, breakfast, and descriptus interruptus. Synthese. v. 128: 45-61.

TEIXEIRA, L. R. 2012. Indexicais e operadores-monstros no Português Brasileiro. Dissertação (mestrado) - Universidade Federal de Santa Catarina: Florianópolis. 